\title{
Percepções de profissionais de saúde e familiares no processo da doação de órgãos para transplante
}

Considerando que a doação de órgãos e tecidos para transplantes é muitas vezes a única opção terapêutica de diversos casos clínicos e que o número de doações é insuficiente de forma universal, é preciso compreender as causas que levam os indivíduos encaram esse processo de forma negativa. $\mathrm{O}$ objetivo Analisar as percepções subjetivas de indivíduos que participaram do processo de doação de órgãos, tanto profissionais como familiares, a fim de identificar os fatores que levam a escolha de doar ou não. Foi realizada uma revisão integrativa com abordagem quantitativa e qualitativa, que buscou publicações dos últimos cinco anos na Bireme e as bases de dados Scielo, Medline e PubMed. A avaliação dos dados quantitativos indicou as características gerais dos estudos incluídos e dos sujeitos que participaram das respectivas pesquisas incluídas, enquanto a análise qualitativa levou a organização de quatro grupos (familiares - potenciais doadores vivos, familiares de indivíduos falecidos, profissionais de saúde e enfermeiros exclusivamente) e suas respectivas percepções sobre o processo de doação de órgãos. A ampliação das percepções dos indivíduos através do acesso a informações e conhecimentos sobre a doação de órgãos pode beneficiar a dinâmica deste processo. A pesquisa evidenciou a necessidade da humanização na assistência a família durante o processo de doação, abertura de espaços para conversas e reflexões sobre o tema, e da melhora do acesso à informação e promoção da educação permanente dos profissionais de saúde.

\section{Perceptions of health professionals and family members in the organ donation process for transplantation}

\footnotetext{
Considering that the donation of organs and tissues for transplants is often the only therapeutic option in several clinical cases and that the number of donations is universally insufficient, it is necessary to understand the causes that lead individuals to view this process in a negative way. The objective To analyze the subjective perceptions of individuals who participated in the organ donation process, both professionals and family members, in order to identify the factors that lead to the choice of donating or not. An integrative review with a quantitative and qualitative approach was carried out, which sought publications from the last five years in Bireme and the Scielo, Medline and PubMed databases. The evaluation of quantitative data indicated the general characteristics of the included studies and the subjects who participated in the respective included studies, while the qualitative analysis led to the organization of four groups (relatives potential living donors, relatives of deceased individuals, health professionals and nurses exclusively and their respective perceptions of the organ donation process. The expansion of individuals' perceptions through access to information and knowledge about organ donation can benefit the dynamics of this process. The research highlighted the need for humanization in family care during the donation process, opening spaces for conversations and reflections on the topic, and improving access to information and promoting continuing education for health professionals.

Keywords: Organ donations; Family perceptions; Health professionals
}

Topic: Enfermagem Geral

Reviewed anonymously in the process of blind peer.

Márcia Féldreman Nunes Gonzaga (iD

Universidade de Sorocaba, Brasil

http://lattes.cnpq.br/3025221287848363

http://orcid.org/0000-0002-8208-6914

marcia.feldreman@gmail.com

Rebeca Gonçalves Trevisano

Faculdade de Ensino Superior Santa Barbara, Brasil

http://lattes.cnpq.br/4838697927012839

http://orcid.org/0000-0002-8456-6778

rebecatrevisano96@gmail.com

Clayton Gonçalves de Almeida

Universidade de Sorocaba, Brasil

http://orcid.org/0000-0003-2959-3965

http://lattes.cnpq.br/6493791537446598

prof.clayton.almeida@faesb.edu.br
Received: 15/02/2021

Approved: 27/04/2021 


\section{INTRODUÇÃO}

O transplante pode ser conceituado como um processo cirúrgico onde há substituição de órgão ou tecido de um indivíduo (doador vivo ou falecido) para o outro, com finalidade de restabelecer a funcionalidade do mesmo (ABTO, 2010). Em muitos casos, o transplante é a única opção terapêutica para pacientes que possuem alguma insuficiência funcional irreversível (WESTPHAL et al., 2016).

Nos últimos anos houve uma ampliação de discussões sobre a doação de órgãos e tecidos para transplantes devido a pouca oferta universal de doações frente à alta demanda de pacientes que precisam de transplante e a necessidade de compreender efetivamente, tanto pelos profissionais e familiares, os aspectos legais e éticos deste processo (RUDGE et al., 2012).

Nesse contexto é essencial identificar as barreiras que afetam as doações de órgãos e tecidos, assim como desenvolver estratégias para transpor esses obstáculos. Pesquisas indicam que alguns problemas que impedem as doações são relacionados à recusa familiar pela falta de conhecimento, por tanto, uma das possíveis estratégias a ser trabalhada é a educação e a transmissão de informações de forma coesa (CAPPELLARO et al., 2014; ARANDA et al., 2018).

Em relação aos profissionais que participam deste processo, em especial os que acompanham a família, realizando a entrevista onde são elucidadas dúvidas e também informando e orientando sobre a doação dos órgãos para transplantes, uma pesquisa realizada no Brasil indicou que os mesmos referem que ainda é necessário fortalecer a educação continuada para aperfeiçoamento dos colaboradores a fim de realizar as atividades deste transcurso complexo com maior eficiência (MARCONDES et al., 2019).

Considerando que as barreiras e as estratégias são estabelecidas a partir das percepções particulares dos indivíduos e que estas abrangem subjetividades, como o estilo de vida, a religiosidade, o acesso à informação, o conhecimento prévio, os aspectos culturais, entre outros fatores (MARTINS et al., 2016), é fundamental observá-las e entendê-las na busca de benefícios, como a segurança, para evolução positiva da dinâmica das doações para transplante.

Portanto, o objetivo desta revisão é analisar pesquisas que descreveram as percepções dos profissionais de saúde e familiares no processo da doação de órgãos ou tecidos para transplante a fim de utilizar essas identificações como facilitadoras de ações em saúde que englobam esse tema.

\section{METODOLOGIA}

A pesquisa desenvolvida é uma revisão integrativa que buscou observar as percepções da equipe de enfermagem no processo de consentimento da doação de órgãos e tecidos para transplantes, considerando especialmente o contexto de luto e subjetividade vivenciados pela família a fim de organizar ações para facilitar esse processo.

A abordagem realizada foi exploratória e quanti-qualitativa. Quantitativamente, foram organizados dados dos participantes dos estudos em: Profissionais, familiares ou doadores potenciais; idade média e gênero desses indivíduos e local de desenvolvimento da pesquisa. Qualitativamente, as percepções dos indivíduos foram sistematizadas em tópicos e discutidas de forma objetiva. 
Foram selecionados estudos que estivessem nos idiomas português, espanhol ou inglês, publicados nos últimos cinco anos e que apresentaram as percepções do profissional de saúde e/ou percepções dos familiares a respeito da doação de órgãos. Os estudos publicados em diferentes idiomas além dos incluídos, publicações com mais de cinco anos, artigos que não apresentaram congruência com o objetivo da revisão e outras revisões de literaturas, trabalhos de conclusão de curso, dissertações, teses e e-books foram excluídos.

As buscas foram realizadas em Setembro de 2020 na Biblioteca Virtual de Saúde (BVS) e nas bases de dados: Scientific Electronic Library Online (SCIELO), PubMed. As principais palavras-chave utilizadas, em português e inglês, foram "processo de doação de órgãos", "família" e "enfermagem", utilizando os operadores Booleanos AND e OR. As estratégias de busca detalhadas estão no quadro A.

Quadro A: Estratégias de busca detalhada na BVS - Bireme: bases de dados Scielo, Medline e PubMed, respectivamente. (organ donation process ) AND (family)

(processo de doação de órgãos) AND (família) OR (familiares) AND (enfermagem) AND (fulltext:("1") AND db:("LILACS" OR "BDENF" OR "MEDLINE") AND la:("pt" OR "en" OR "es") AND year_cluster:("2017" OR "2016" OR "2018" OR "2019" OR "2020"))

((()(()(("tissue and organ procurement"[MeSH Terms] OR (("tissue"[All Fields] AND "organ"[All Fields]) AND "procurement"[All Fields])) OR "tissue and organ procurement"[All Fields]) OR ("organ"[All Fields] AND "donation"[All Fields])) OR "organ donation"[All Fields]) OR "organ transplantation"[MeSH Terms]) OR ("organ"[All Fields] AND "transplantation"[All Fields])) OR "organ transplantation"[All Fields]) OR ("organ"[All Fields] AND "donation"[All Fields])) AND (((("process"[All Fields] OR "processe"[All Fields]) OR "processed"[All Fields]) OR "processes"[All Fields]) OR "processing"[All Fields]) OR "processings"[All Fields])) AND ((()(()(("familialities"[All Fields] OR "familiality"[All Fields]) OR "familially"[All Fields]) OR "familials"[All Fields]) OR "familie"[All Fields]) OR "family"[MeSH Terms]) OR "family"[All Fields]) OR "familial"[All Fields]) OR "families"[All Fields]) OR "family s"[All Fields]) OR "familys"[All Fields])) AND "nurs*"[All Fields]

\section{RESULTADOS}

Foram encontradas 89 publicações no total, após a exclusão de duplicações restaram 85 artigos. Destes, foram excluídos 50 após a leitura do título e resumo, restando 35 pesquisas, que foram lidas na íntegra. Por fim, 16 artigos atenderam aos critérios de seleção após análise e fizeram parte desta revisão. 0 processo de seleção dos mesmos pode ser observado no fluxograma abaixo.

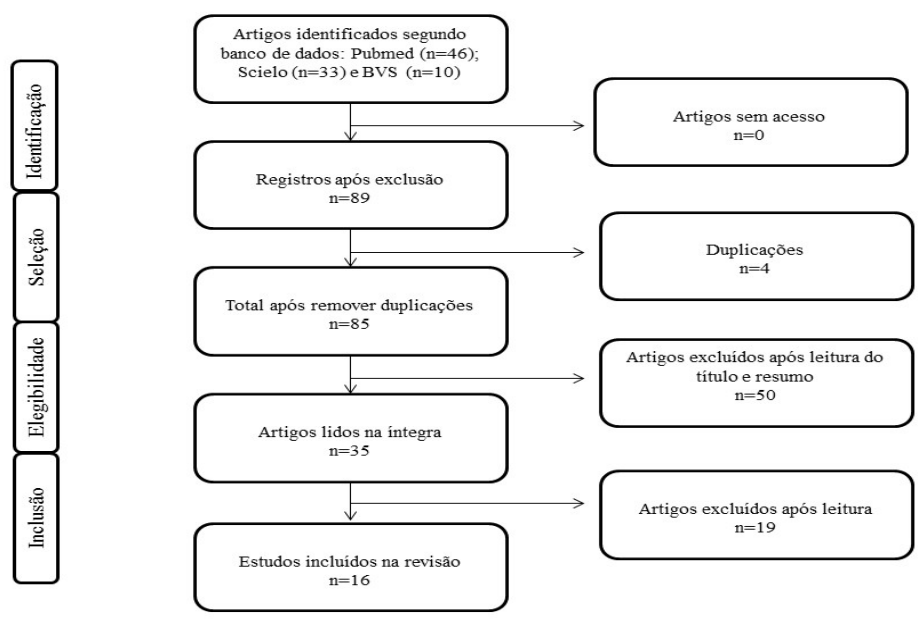

Figura 1: Fluxograma de seleção dos artigos. 
A maior parte dessas pesquisas foi conduzida no Brasil, representando um total de 37,5\% (ARAUJO et al., 2016; FONSECA et al., 2016; MAGALHÃES et al., 2018; MARCONDES et al., 2019; ROSSATO et al., 2017; VICTORINO et al., 2017), seguido do Reino Unido, representando 12,5\% (DOPSON et al., 2019; WALKER et al., 2019A) e outros estudos foram conduzidos no Chile (PEREIRA et al., 2016), na África do Sul (BOOKHOLANE et al., 2020), no Peru (MORAN et al., 2018), na Dinamarca (AGERSKOV et al., 2018), no Irã (RAHIMI et al., 2017), na Espanha (SALINAS et al., 2018), Sérvia (VLAISAVLEVICA et al., 2020) e Nova Zelândia (WALKER et al., 2019).

No total foram incluídos 979 participantes, entre profissionais e familiares, que passaram pelo processo de doação de órgãos e tecidos para transplantes. Em relação aos participantes, $85 \%$ eram profissionais de saúde, destes 30,1\% foram exclusivamente enfermeiros (DOPSON et al., 2019; MAGALHÃES et al., 2018; MARCONDES et al., 2019; PEREIRA et al., 2016; VLAISAVLEVICA et al., 2020) e 54,8\% dos estudos abordaram equipe multidisciplinar ou mais de uma categoria de trabalhadores (ARAUJO et al., 2016; FONSECA et al., 2016; SALINAS et al., 2018; VICTORINO et al., 2017).

Os demais indivíduos foram categorizados como familiares, representando $15 \%$ do total de indivíduos, a maior parte dos participantes compartilharam suas percepções acerca do processo de doação de órgãos de familiares falecidos (BOOKHOLANE et al., 2020; RAHIMI et al., 2017; ROSSATO et al., 2017; WALKER et al., 2019) e os demais relataram a experiência como potenciais doadores vivos (AGERSKOV et al., 2018; MORAN et al., 2018; WALKER et al., 2019).

Em geral, grande parte das pesquisas $(68,75 \%)$ (tanto as realizadas com profissionais como com familiares) não indicou a idade média dos mesmos. Apenas 31,25\% apresentaram esses dados em seus resultados, onde 18,75\% eram estudos com profissionais (ARAUJO et al., 2016; SALINAS et al., 2018; VICTORINO e VENTURA, 2017) e 12,5\% com familiares (BOOKHOLANE et al., 2020; RAHIMI et al., 2017), sendo a média de idade geral dos participantes entre os estudos de 44,3 anos.

O gênero dos participantes também foi quantificado, $12,5 \%$ das pesquisas foram realizadas com participantes do sexo feminino (DOPSON et al., 2019; PEREIRA et al., 2016), 56,25\% com participantes de ambos o sexos (AGERSKOV et al., 2018; ARAUJO et al., 2016; BOOKHOLANE et al., 2020; MAGALHÃES et al., 2018; MORAN et al., 2018; RAHIMI et al., 2017; SALINAS et al., 2018; VLAISAVLEVICA et al., 2020; WALKER et al., 2019), 31,25\% dos estudos não referiu o gênero de seus participantes (FONSECA et al., 2016; MARCONDES et al., 2019; ROSSATO et al., 2017; VICTORINO e VENTURA., 2017; WALKER et al., 2019A) e nenhum deles foi realizado exclusivamente com uma população masculina.

Abaixo, o quadro B apresenta os estudos incluídos, indicando o autor principal, ano de publicação, título de artigo, a revista no qual o mesmo foi publicado e seus objetivos e resultados principais. $\mathrm{O}$ quadro B1, com os dados principais dos artigos excluídos poderá ser consultado em material suplementar. 
Quadro B: Características gerais dos participantes.

\begin{tabular}{|c|c|c|c|c|c|c|}
\hline \multicolumn{7}{|c|}{ Artigos incluídos } \\
\hline $\begin{array}{c}\text { Autor } \\
\text { principal }\end{array}$ & Ano & Título & $\begin{array}{c}\text { Revista ou } \\
\text { periódico (ISSN) }\end{array}$ & $\begin{array}{l}\text { Tipo de } \\
\text { estudo }\end{array}$ & $\begin{array}{c}\text { Objetivo principal do } \\
\text { estudo }\end{array}$ & Resultados principais \\
\hline Agerskov & 2018 & $\begin{array}{l}\text { Parents' experiences of } \\
\text { donation to their child } \\
\text { before kidney } \\
\text { transplantation: A } \\
\text { qualitative study }\end{array}$ & $\begin{array}{l}\text { J Clin Nurs (1365- } \\
\text { 2702) }\end{array}$ & $\begin{array}{l}\text { Estudo } \\
\text { qualitativo e } \\
\text { exploratório }\end{array}$ & $\begin{array}{l}\text { Analisar as percepções } \\
\text { e emoções de pais no } \\
\text { processo de } \\
\text { transplante renal de } \\
\text { seus filhos }\end{array}$ & $\begin{array}{l}\text { Neste estudo os pais foram } \\
\text { considerados como } \\
\text { potenciais doadores vivos. Os } \\
\text { principais sentimentos } \\
\text { notados foram o de doar de } \\
\text { forma incondicional para os } \\
\text { filhos, com alegria quando } \\
\text { foram aceitos e quando } \\
\text { rejeitados, sentiram-se } \\
\text { impotentes. }\end{array}$ \\
\hline Araujo & 2016 & $\begin{array}{l}\text { Brazilian Healthcare } \\
\text { Professionals: A Study } \\
\text { of Attitudes Toward } \\
\text { Organ Donation }\end{array}$ & $\begin{array}{l}\text { Transplantation } \\
\text { Proceedings } \\
(1873-2623)\end{array}$ & $\begin{array}{l}\text { Estudo } \\
\text { transversal e } \\
\text { qualitativo }\end{array}$ & $\begin{array}{l}\text { Analisar as atitudes de } \\
\text { profissionais de dois } \\
\text { hospitais do Rio de } \\
\text { Janeiro frente à } \\
\text { doação de órgãos para } \\
\text { transplantes e } \\
\text { possíveis fatores que } \\
\text { podem afetar o } \\
\text { posicionamento dos } \\
\text { mesmos. }\end{array}$ & $\begin{array}{l}\text { A maior parte dos } \\
\text { profissionais teve uma } \\
\text { atitude positiva em relação à } \\
\text { doação, assim, os autores } \\
\text { apontam que o } \\
\text { conhecimento sobre o } \\
\text { processo pode influenciar na } \\
\text { decisão ressaltando a } \\
\text { necessidade de campanhas } \\
\text { de conscientização pública } \\
\text { para ampliação do acesso à } \\
\text { informação. }\end{array}$ \\
\hline Bookholane & 2020 & $\begin{array}{l}\text { Factors influencing } \\
\text { consent rates of } \\
\text { deceased organ } \\
\text { donation in Western } \\
\text { Cape Province, South } \\
\text { Africa }\end{array}$ & $\begin{array}{l}\text { South African } \\
\text { Medical Journal } \\
(2078-5135)\end{array}$ & $\begin{array}{c}\text { Estudo } \\
\text { descritivo } \\
\text { prospectivo }\end{array}$ & $\begin{array}{l}\text { Verificar o número de } \\
\text { consentimentos para } \\
\text { doação de órgãos e os } \\
\text { fatores que } \\
\text { influenciam a decisão } \\
\text { dos familiares neste } \\
\text { processo no contexto } \\
\text { da África do Sul }\end{array}$ & $\begin{array}{l}\text { O consentimento familiar foi } \\
\text { baixo e motivado } \\
\text { principalmente por aspectos } \\
\text { religiosos e culturais }\end{array}$ \\
\hline Dopson & 2019 & $\begin{array}{l}\text { Exploring nurses' } \\
\text { knowledge, attitudes } \\
\text { and feelings towards } \\
\text { organ and tissue } \\
\text { donation after } \\
\text { circulatory death within } \\
\text { the paediatric intensive } \\
\text { care setting in the } \\
\text { United Kingdom: A } \\
\text { qualitative content } \\
\text { analysis study }\end{array}$ & $\begin{array}{l}\text { Intensive \& } \\
\text { Critical Care } \\
\text { Nursing (0964- } \\
\text { 3397) }\end{array}$ & $\begin{array}{l}\text { Estudo } \\
\text { qualitativo }\end{array}$ & $\begin{array}{l}\text { Explorar o } \\
\text { conhecimento e } \\
\text { percepções de } \\
\text { enfermeiros em } \\
\text { relação à doação de } \\
\text { órgãos }\end{array}$ & $\begin{array}{l}\text { De forma geral, os } \\
\text { profissionais relataram, } \\
\text { principalmente, sentirem-se } \\
\text { despreparados para agir e } \\
\text { instruir famílias no processo } \\
\text { de doação. }\end{array}$ \\
\hline Fonseca & 2016 & $\begin{array}{l}\text { Entrevista familiar para } \\
\text { doação de órgãos: } \\
\text { conhecimentos } \\
\text { necessários segundo } \\
\text { coordenadores em } \\
\text { transplantes }\end{array}$ & $\begin{array}{l}\text { Revista de } \\
\text { Pesquisa: } \\
\text { Cuidado é } \\
\text { Fundamental } \\
\text { Online (2175- } \\
5361)\end{array}$ & $\begin{array}{l}\text { Estudo } \\
\text { qualitativo }\end{array}$ & $\begin{array}{l}\text { Compreender a } \\
\text { importância da } \\
\text { entrevista familiar na } \\
\text { doação de órgãos pela } \\
\text { equipe } \\
\text { multidisciplinar e } \\
\text { identificar os } \\
\text { conhecimentos } \\
\text { necessários para } \\
\text { realização da mesma. }\end{array}$ & $\begin{array}{l}\text { A entrevista foi apontada } \\
\text { como um dos momentos } \\
\text { mais importantes no } \\
\text { processo de doação e, para } \\
\text { realizá-la, destacam-se a } \\
\text { necessidade do } \\
\text { conhecimento teórico e do } \\
\text { preparo emocional. }\end{array}$ \\
\hline Magalhães & 2018 & $\begin{array}{l}\text { Significados do cuidado } \\
\text { de enfermagem ao } \\
\text { paciente em morte } \\
\text { encefálica potencial } \\
\text { doador }\end{array}$ & $\begin{array}{l}\text { Revista Gaúcha } \\
\text { de Enfermagem } \\
(1983-1447)\end{array}$ & $\begin{array}{l}\text { Estudo } \\
\text { qualitativo }\end{array}$ & $\begin{array}{l}\text { Avaliar as percepções } \\
\text { de enfermeiros } \\
\text { atuantes em unidade } \\
\text { de terapia intensiva } \\
\text { acerca dos cuidados } \\
\text { com paciente em ME } \\
\text { (potencial doador) }\end{array}$ & $\begin{array}{l}\text { Os enfermeiros relataram } \\
\text { que o processo de cuidados } \\
\text { com paciente em ME e } \\
\text { potencial doador é complexo } \\
\text { e fundamental para } \\
\text { efetividade da doação, sendo } \\
\text { essencial o olhar para este } \\
\text { paciente como um gerador } \\
\text { de vida por meio da doação } \\
\text { de órgãos }\end{array}$ \\
\hline Marcondes & 2019 & $\begin{array}{l}\text { Abordagem familiar } \\
\text { para a doação de } \\
\text { órgãos: Percepção dos } \\
\text { enfermeiros }\end{array}$ & $\begin{array}{l}\text { Revista de } \\
\text { Enfermagem } \\
\text { UFPE online } \\
\text { (1981-8963) }\end{array}$ & $\begin{array}{c}\text { Estudo } \\
\text { qualitativo, } \\
\text { explicativo e } \\
\text { exploratório }\end{array}$ & $\begin{array}{l}\text { Identificar a } \\
\text { percepção de } \\
\text { enfermeiros a respeito } \\
\text { da abordagem familiar } \\
\text { no processo de } \\
\text { doação de órgãos. }\end{array}$ & $\begin{array}{l}\text { Através das percepções dos } \\
\text { enfermeiros, é concluído que } \\
\text { as instituições de saúde } \\
\text { precisam investir na } \\
\text { educação permanente para } \\
\text { qualificação dos } \\
\text { colaboradores, assim como } \\
\text { divulgar e informar a } \\
\text { população geral. }\end{array}$ \\
\hline
\end{tabular}




\begin{tabular}{|c|c|c|c|c|c|c|}
\hline Moran & 2018 & $\begin{array}{l}\text { El amor, resonancia } \\
\text { esencial del cuidado } \\
\text { para La vida, desde la } \\
\text { experiencia del familiar } \\
\text { donante renal vivo. } \\
\text { Lima (Perú) }\end{array}$ & $\begin{array}{l}\text { Salud Uninorte } \\
\text { (2011-7531) }\end{array}$ & $\begin{array}{l}\text { Estudo } \\
\text { qualitativo, } \\
\text { descritivo e } \\
\text { exploratório }\end{array}$ & $\begin{array}{l}\text { Descrever os } \\
\text { sentimentos de } \\
\text { familiares que doaram } \\
\text { o rim (doadores vivos) } \\
\text { durante o processo de } \\
\text { doação }\end{array}$ & $\begin{array}{l}\text { O principal sentimento } \\
\text { percebido e que também } \\
\text { impulsionou a doação foi o } \\
\text { amor e o desejo de manter o } \\
\text { ente querido vivo. }\end{array}$ \\
\hline Pereira & 2016 & $\begin{array}{l}\text { Representações sociais } \\
\text { dos profissionais de } \\
\text { enfermagem da } \\
\text { unidade do paciente } \\
\text { crítico adulto em } \\
\text { relação à doação de } \\
\text { órgãos }\end{array}$ & $\begin{array}{l}\text { Enfermería: } \\
\text { Cuidados } \\
\text { Humanizados } \\
(2393-6606)\end{array}$ & $\begin{array}{l}\text { Estudo } \\
\text { qualitativo }\end{array}$ & $\begin{array}{l}\text { Compreender as } \\
\text { representações sociais } \\
\text { de enfermeiros } \\
\text { atuantes em unidade } \\
\text { de terapia intensiva } \\
\text { frente à doação de } \\
\text { órgãos }\end{array}$ & $\begin{array}{l}\text { As enfermeiras relataram que } \\
\text { o processo de doação de } \\
\text { órgãos é complexo com } \\
\text { consequente sobrecarga } \\
\text { emocional e de trabalho, } \\
\text { destacando ainda fatores } \\
\text { limitantes como a decisão da } \\
\text { família, falta de profissionais } \\
\text { especializados e poucos leitos } \\
\text { na UTI. }\end{array}$ \\
\hline Rahimi & 2017 & $\begin{array}{l}\text { Outcomes of organ } \\
\text { donation in brain-dead } \\
\text { patient's families: } \\
\text { Ethical perspective }\end{array}$ & $\begin{array}{l}\text { Nursing Ethics } \\
(1980-265 X)\end{array}$ & $\begin{array}{l}\text { Estudo } \\
\text { descritivo } \\
\text { qualitativo }\end{array}$ & $\begin{array}{l}\text { Compreender os } \\
\text { sentimentos dos } \\
\text { familiares de } \\
\text { pacientes em morte } \\
\text { encefálica sobre o } \\
\text { processo de doação } \\
\text { de órgãos para } \\
\text { transplantes. }\end{array}$ & $\begin{array}{l}\text { Os sentimentos frente à } \\
\text { doação foram positivamente } \\
\text { associados ao carinho, } \\
\text { transcendência espiritual e } \\
\text { outros aspectos relacionados } \\
\text { à religião e cultura. Sendo } \\
\text { que os pontos negativos } \\
\text { foram associados à dor e } \\
\text { complexidade da situação }\end{array}$ \\
\hline Rossato & 2017 & $\begin{array}{l}\text { Doar ou não doar: A } \\
\text { visão de familiares } \\
\text { frente à doação de } \\
\text { órgãos }\end{array}$ & $\begin{array}{l}\text { Rev Min Enferm } \\
(2316-9389)\end{array}$ & $\begin{array}{l}\text { Estudo } \\
\text { qualitativo, } \\
\text { descritivo e } \\
\text { exploratório } \\
\text { (estudo de } \\
\text { caso) }\end{array}$ & $\begin{array}{l}\text { Compreender os } \\
\text { motivos que } \\
\text { influenciam a decisão } \\
\text { da família frente à } \\
\text { doação ou não doação } \\
\text { de órgãos de um } \\
\text { familiar adulto. }\end{array}$ & $\begin{array}{l}\text { Os familiares apresentaram } \\
\text { motivos para doar ou não, } \\
\text { sendo o principal motivo da } \\
\text { não doação o respeito à } \\
\text { vontade do potencial doador } \\
\text { em vida ou falta de } \\
\text { conhecimento da mesma. Em } \\
\text { relação à aceitação, a } \\
\text { motivação era ajudar o } \\
\text { próximo e também respeitar } \\
\text { o desejo do familiar. }\end{array}$ \\
\hline Salinas & 2018 & $\begin{array}{l}\text { Knowledge and } \\
\text { attitudes toward organ } \\
\text { donation among health } \\
\text { professionals in a third } \\
\text { level hospital }\end{array}$ & $\begin{array}{l}\text { Rev Esp Salud } \\
\text { Pública (2173- } \\
\text { 9110) }\end{array}$ & $\begin{array}{l}\text { Estudo } \\
\text { descritivo } \\
\text { transversal }\end{array}$ & $\begin{array}{l}\text { Analisar o } \\
\text { conhecimento e } \\
\text { atitudes de } \\
\text { profissionais de saúde } \\
\text { frente ao processo de } \\
\text { doação de órgãos }\end{array}$ & $\begin{array}{l}\text { Os profissionais } \\
\text { apresentaram atitudes } \\
\text { positivas em relação à } \\
\text { doação de órgãos para } \\
\text { transplantes, sendo que } \\
\text { alguns aspectos negativos } \\
\text { foram associados à falta de } \\
\text { conhecimento. Os autores } \\
\text { sugerem uma intervenção } \\
\text { educacional para qualificar os } \\
\text { profissionais e facilitar o } \\
\text { processo de doação } \\
\text { simultaneamente. }\end{array}$ \\
\hline Victorino & 2017 & $\begin{array}{l}\text { Doação de órgãos: } \\
\text { tema bioético à luz da } \\
\text { legislação }\end{array}$ & $\begin{array}{l}\text { Rev bioét (1983- } \\
8034)\end{array}$ & $\begin{array}{l}\text { Estudo } \\
\text { qualitativo }\end{array}$ & $\begin{array}{l}\text { Observar a opinião de } \\
\text { profissionais de saúde } \\
\text { que atuam no } \\
\text { processo de doação } \\
\text { de órgãos sobre a } \\
\text { implementação da Lei } \\
10.211 / 2001\end{array}$ & $\begin{array}{l}\text { Os profissionais acreditam } \\
\text { que a legislação é importante } \\
\text { para assegurar o processo de } \\
\text { doação, considerando ainda } \\
\text { necessário a educação } \\
\text { continuada para qualificação } \\
\text { e conhecimento dos } \\
\text { dispositivos legais a fim de } \\
\text { melhorar o atendimento } \\
\text { eficiente, humanizado e } \\
\text { ético. }\end{array}$ \\
\hline Vlaisavljevica & 2020 & $\begin{array}{l}\text { Attitudes of Nurses } \\
\text { Toward Organ } \\
\text { Donation in Serbia }\end{array}$ & $\begin{array}{l}\text { Transplantation } \\
\text { Proceedings } \\
\text { (1873-2623) }\end{array}$ & $\begin{array}{l}\text { Estudo } \\
\text { transversal }\end{array}$ & $\begin{array}{l}\text { Verificar os fatores } \\
\text { que influenciam os } \\
\text { profissionais em } \\
\text { relação à doação de } \\
\text { órgãos para } \\
\text { transplante }\end{array}$ & $\begin{array}{l}\text { Em geral, os profissionais } \\
\text { tinham um posicionamento } \\
\text { negativo associado à falta de } \\
\text { conhecimento sobre o } \\
\text { processo de doação. Assim, } \\
\text { os autores enfatizam } \\
\text { importância de intervenções } \\
\text { educacionais para população } \\
\text { geral e para profissionais } \\
\text { também. }\end{array}$ \\
\hline
\end{tabular}




\begin{tabular}{|c|c|c|c|c|c|c|}
\hline Walker & 2019 & $\begin{array}{l}\text { Parents' perspectives } \\
\text { and experiences of } \\
\text { kidney transplantation } \\
\text { in children: a } \\
\text { qualitative interview } \\
\text { study }\end{array}$ & $\begin{array}{l}\text { Journal of Renal } \\
\text { Care (1755-6686) }\end{array}$ & $\begin{array}{l}\text { Estudo } \\
\text { transversal }\end{array}$ & $\begin{array}{l}\text { Explorar as } \\
\text { perspectivas e } \\
\text { experiências dos pais } \\
\text { de crianças que foram } \\
\text { submetidas a } \\
\text { transplante renal. }\end{array}$ & $\begin{array}{l}\text { Os familiares apresentaram } \\
\text { um misto de sentimentos e } \\
\text { em geral, o estresse e } \\
\text { pressões aumentaram muito. } \\
\text { Os autores concluíram que é } \\
\text { necessário maior suporte } \\
\text { familiar ofertado pela equipe } \\
\text { de saúde. }\end{array}$ \\
\hline Walker & $2019 A$ & $\begin{array}{l}\text { Family bereavement: A } \\
\text { case study of controlled } \\
\text { organ donation after } \\
\text { circulatory death }\end{array}$ & $\begin{array}{l}\text { Nurs Crit Care } \\
(1478-5153)\end{array}$ & $\begin{array}{l}\text { Estudo } \\
\text { qualitativo }\end{array}$ & $\begin{array}{l}\text { Analisar os aspectos } \\
\text { subjetivos e } \\
\text { percepções de } \\
\text { familiares em relação } \\
\text { à decisão de doar os } \\
\text { órgãos de um ente } \\
\text { querido em morte } \\
\text { circulatória. }\end{array}$ & $\begin{array}{l}\text { Os familiares relatam que o } \\
\text { processo de doação foi } \\
\text { complexo, fatores como a } \\
\text { vontade do falecido foi } \\
\text { considerada. Ainda foi } \\
\text { relatado que a doação } \\
\text { auxiliou no processo de luto. }\end{array}$ \\
\hline
\end{tabular}

No quadro C estão organizadas as categorias de participantes, gênero e idade média, bem como o local onde a pesquisa foi desenvolvida, segundo as respectivas referências (autor principal e ano de publicação).

Quadro C: Características gerais dos participantes.

\begin{tabular}{|c|c|c|c|c|}
\hline Referência & Característica dos indivíduos (n) & Idade média (anos) & Gênero & Local \\
\hline Agerskov, 2018 & Familiares -potenciais doadores vivos (14) & Não referido & Feminino e Masculino & Dinamarca \\
\hline Araujo, 2016 & Profissionais de saúde - médicos e enfermeiros (162) & 35 & Feminino e Masculino & Brasil \\
\hline Bookholane, 2020 & Familiares (83) & 49 & Feminino e Masculino & África do Sul \\
\hline Dopson, 2019 & Enfermeiras (8) & Não referido & Feminino & Reino Unido \\
\hline Fonseca, 2016 & Profissionais de saúde (24) & Não referido & Não referido & Brasil \\
\hline Magalhães, 2018 & Enfermeiros (12) & Não referido & Feminino e Masculino & Brasil \\
\hline Marcondes, 2019 & Enfermeiros (6) & Não referido & Não referido & Brasil \\
\hline Moran, 2018 & Familiares - potenciais doadores vivos (6) & Não referido & Feminino e Masculino & Peru \\
\hline Pereira, 2016 & Enfermeiras (5) & Não referido & Feminino & Chile \\
\hline Rahimi, 2017 & Familiares (19) & 46,2 & Feminino e Masculino & Irã \\
\hline Rossato, 2017 & Familiares (8) & Não referido & Não referido & Brasil \\
\hline Salinas, 2018 & Profissionais de saúde (342) & 43,3 & Feminino e Masculino & Espanha \\
\hline Victorino, 2017 & Profissionais de saúde (9) & 48 & Não referido & Brasil \\
\hline Vlaisavljevica, 2020 & Enfermeiros (264) & Não referido & Feminino e Masculino & Sérvia \\
\hline Walker, 2019 & Familiares - potenciais doadores vivos (17) & Não referido & Feminino e Masculino & Nova Zelândia \\
\hline Walker, 2019A & Familiares (não referido) & Não referido & Não referido & Reino Unido \\
\hline
\end{tabular}

\section{DISCUSSÃO TEÓRICA}

A análise qualitativa foi organizada em quatro categorias relacionadas às percepções, sentimentos e subjetividades em geral dos sujeitos acerca do processo de doação de órgãos, sendo elas: Sentimentos e percepções de potenciais doadores vivos; de familiares de doadores falecidos ou em morte circulatória ou morte encefálica; dos profissionais de saúde em geral e de enfermeiros.

O primeiro grupo, composto por familiares de potenciais doadores falecidos ou que estavam em morte circulatória ou morte encefálica, relatam suas percepções sobre todo o processo de doação, os fatores que influenciaram a decisão de doar ou não e como se sentiram após essa tomada de decisão (BOOKHOLANE et al., 2020; RAHIMI et al., 2017; ROSSATO et al., 2017; WALKER et al., 2019).

Os resultados mostraram que no segundo grupo (potenciais doadores vivos), todos eram familiares (pais, mães, irmãs, irmãos) que foram considerados como doadores em potencial para realizar doação de rim, eles relataram as emoções durante o processo de transplante, como as expectativas de poder doar e a percepção da doação de órgãos em geral após essa experiência (AGERSKOV et al., 2018; MORAN et al., 2018; WALKER et al., 2019).

Os dois últimos grupos, de profissionais de saúde e de enfermeiros exclusivamente, relataram suas 
percepções pessoais sobre a doação de órgãos e tecidos para transplante e também os sentimentos envolvidos no acompanhamento da família que passa por esse processo, em especial os familiares que precisam decidir sobre a doação de órgãos em paciente falecidos ou quando ocorre a morte circulatória ou encefálica.

\section{A percepção dos familiares de potenciais doadores falecidos}

Nesta categoria, a maior parte dos familiares se posicionou de forma positiva frente à possibilidade da doação de órgãos, assim como apresentaram receptividade para aprender mais sobre o tema.

Os motivos de recusa na doação foram à complexidade do processo de luto, ou seja, precisar tomar essa decisão com forte sentimento de dor e tristeza pela perda (RAHIMI et al., 2017), o respeito à decisão, a vontade do potencial doador em vida ou o desconhecimento dessa vontade também foram fortes influenciadores na tomada de decisão pela família (ROSSATO et al., 2017; WALKER et al., 2019).

Em relação aos aspectos religiosos, dois estudos associaram a religiosidade aos sentimentos e a mesma como fator potencial para doação, sendo que as percepções foram diferentes entre eles. Na primeira pesquisa, desenvolvida no Irã, Rahimi et al. (2017) observaram que os participantes associaram a doação a transcendência espiritual e altruísmo associados à paz de espírito. No entanto, na África do Sul, os participantes relataram não doar os órgãos dos seus entes queridos por aspectos não definidos e que foram associados de forma geral, a cultura e religiosidade (BOOKHOLANE et al., 2020).

As decisões de doar foram baseadas principalmente nos sentimentos altruístas em ajudar o próximo (RAHIMI et al., 2017; ROSSATO et al, 2017; WALKER et al., 2019), a vontade do doador em vida (ROSSATO et al, 2017; WALKER et al., 2019) e aspectos culturais e espirituais (RAHIMI et al., 2017).

Um dos estudos destacou que a decisão da doação de órgãos, baseada na vontade do indivíduo e no consenso familiar, auxiliou no processo de luto, sobretudo em relação à percepção de que a morte deste ente querido teve sentido e significado ao ajudar o próximo (WALKER et al., 2019).

\section{A percepção dos familiares como potenciais doadores vivos}

Neste tópico, todos os participantes eram familiares que foram considerados como potenciais doadores vivos. A perspectiva de doação para um familiar próximo (entre pais, mães, filhos e irmãos) foi positiva de forma unânime.

A pesquisa desenvolvida por Moran et al. (2018), constatou que o sentimento de doação entre familiares é motivado essencialmente pelo amor, outras emoções citadas foram à esperança, carinho e perspectiva de ajudar a manter vivo e bem seu ente querido, assim, a luta pela sobrevivência do familiar é o que move a doação permeada por esses sentimentos.

Os dois outros estudos foram realizados com pais que poderiam ser doadores para seus filhos (crianças ou adolescentes). Walker et al. (2019) destacaram o misto de emoções envolvidos nesse processo, principalmente o estresse emocional e financeiro, o sentimento de despreparo frente a cuidados dos filhos após o transplante, a importância da equipe de saúde (tanto de forma positiva como negativa, a 
participação dos profissionais de saúde se mostrou fortemente influente) e conflitos entre o casal pela sobrecarga geral.

Para os entrevistados, a perspectiva de ser potencial doador foi bem-vinda e trouxe esperança e alegria, no entanto, os demais problemas e sentimentos de estresse, mudança na rotina, acabaram tornando essa possibilidade um novo ponto de discussão e sobrecarga entre os pais.

Agerskovet al. (2018), observou que em sua pesquisa, que também abordou pais como potenciais doadores vivos para seus filhos, o desejo de doar, com sentimentos de felicidade e esperança se pudessem realizar a doação e quando não aceitos, o sentimento principal foi o de impotência.

É interessante destacar, que os pais não gostariam que seus filhos recebessem o rim de doador falecido, relacionando este fato a pensamentos de tragédias. Além disso, quando questionados sobre a doação para outras pessoas, os participantes adotaram um posicionamento reflexivo e com forte possibilidade de não doar relatada pelos mesmos.

\section{A percepção dos profissionais de saúde}

O processo de doação de órgãos e as percepções individuais sobre doar ou não, foram em geral, encarados de forma positiva pelos profissionais. O principal fator associado aos posicionamentos favoráveis a doação de órgãos foi o nível educacional e os conhecimentos sobre o processo de doação, sendo que este aspecto foi considerado benéfico para a construção das opiniões pessoais e também como fator facilitador para o acompanhamento dos familiares e consequentemente para tomada de decisão dos mesmos (ARAUJO et al., 2016; FONSECA et al., 2016; SALINAS et al., 2018; VICTORINO et al, 2017).

No contexto das intervenções educacionais, apenas um dos estudos (SALINAS et al., 2018) verificou limitações significativas dos profissionais em relação aos conhecimentos sobre o processo de doação, porém, os mesmos relataram que gostariam que houvesse mais investimento e oportunidades para qualificação. Os profissionais ainda ressaltam que o preparo através da educação permanente aumentaria a eficiência da dinâmica do processo de doação, como no aprimoramento para condução da entrevista familiar (FONSECA et al., 2016).

Um estudo observou que os participantes acreditam ser necessário estabelecer e implementar legislações, protocolos e outras diretrizes legais para elevar a qualidade e segurança no processo de doação de órgãos, ressaltando que as estratégias educativas devem acompanhar em sincronia essas disposições legais, à medida que são transmitidas e ensinadas para os trabalhadores de saúde (VICTORINO et al., 2017).

Outro fator importante no posicionamento favorável frente à doação de órgãos e tecidos foi à expectativa de poder salvar vidas através desse processo (ARAUJO et al., 2016).

\section{A percepção dos enfermeiros}

As pesquisas realizadas exclusivamente com enfermeiros mostraram que a maioria dos participantes foi favorável a doação de órgãos e tecidos para transplante e referiram sentimentos complexos, diversos e contraditórios associados a este processo e ao acompanharem uma família 
(MAGALHÃES et al., 2019; MARCONDES et al., 2019; PEREIRA et al., 2016).

Apenas em uma das pesquisas, conduzida na Sérvia, os participantes tiveram um posicionamento negativo e não foram a favor da doação de órgãos, os mesmos ressaltaram que possuíam conhecimentos muito limitados sobre o tema e acreditavam que suas percepções poderiam mudar se pudessem aprender mais sobre o processo de doação (VLAISAVLEVICA et al., 2020).

Em outros estudos, os enfermeiros relataram sentirem-se despreparados para instruir as famílias sobre a doação (DOPSON et al., 2019) e que a complexidade de acompanhar as famílias de potenciais doadores, assim como cuidar destes doadores quando em morte circulatória ou morte encefálica, gerava sobrecarga física e emocional (MAGALHÃES et al., 2019; PEREIRA et al., 2016).

Os participantes relataram que alguns aspectos negativos percebidos sobre o processo de doação foram à sensação de despreparo, ansiedade e insegurança na abordagem familiar, sobrecarga física e emocional (associada à falta de recursos humanos e/ou materiais), a dualidade do ser enfermeiro (equilibrar o profissional e os sentimentos pessoais), falta de preparo emocional e limitações educacionais, como a dificuldade em esclarecer para família o conceito de morte encefálica (DOPSON et al., 2019; MAGALHÃES et al., 2019; PEREIRA et al., 2016).

Neste contexto, foram apontados alguns facilitadores e estratégias para melhorar a qualidade no processo de doação, como o fortalecimento do vínculo com a família, parceria com a Comissão Intrahospitalar de Doação de Órgãos e Tecidos para Transplantes (CIHDOTT), interação com a equipe multiprofissional, implantação de políticas públicas específicas, assim como protocolos e diretrizes de cuidados, conscientização da população através de acesso à informação e qualificação dos profissionais com intervenções educacionais (DOPSON et al., 2019; MAGALHÃES et al., 2019; MARCONDES et al., 2019; PEREIRA et al., 2016).

Marcondes et al. (2019) destacam ainda alguns aspectos a ser evitado durante a entrevista familiar, etapa considerada fundamental no processo de doação, como a adoção de uma atitude impositiva, não esclarecer dúvidas ou demonstrar pressa. Além disso, os autores destacam a importância da boa comunicação, verbal e não verbal, bem como o bom senso no acompanhamento familiar.

As publicações resultantes que foram incluídas nesta revisão procuraram analisar as percepções, sentimentos e demais aspectos subjetivos dos sujeitos que participaram do processo de doação de órgãos para transplantes.

Em relação aos familiares, os posicionamentos positivos frente à doação de órgãos, foram associados fortemente a sentimentos de amor, carinho, fraternidade, esperança, caridade e percepção da doação como um ato promotor da vida (RAHIMI et al., 2017; ROSSATO et al, 2017; WALKER et al., 2019; MORAN et al. 2018), sendo que esses sentimentos quando relacionados à cultura e religião tiveram divergências (RAHIMI et al., 2017; BOOKHOLANE et al., 2020).

Os participantes da pesquisa realizada por Rahimiet al. (2017) apontaram a religião como fortalecedora da decisão de doar órgãos associada à transcendência espiritual deste ato, enquanto os indivíduos que participaram da pesquisa de Bookholane et al. (2020) afirmaram que a recusa a doação era 
motivada principalmente por questões religiosas e culturais.

É importante destacar que essas diferenças podem ser justificadas pelos contextos nos quais os participantes estavam inseridos, visto que uma das pesquisas foi realizada no Irã (RAHIMI et al., 2017) e a outra na África do Sul (BOOKHOLANE et al., 2020). No entanto, Ferrazzo et al. (2011) apontam que a maioria das religiões não restringe absolutamente a doação de órgãos e grande parte observa esse processo como um ato de amor e caridade.

Outros aspectos que se relacionaram a recusa familiar foram à complexidade e a fragilidade pela vivência do luto (RAHIMI et al., 2017; ROSSATO et al., 2017; WALKER et al., 2019A), esses fatores ressaltam a necessidade da equipe profissional estar bem preparada para oferecer suporte à família, aplicando cuidados humanizados eficientes para promoção do conforto emocional e ações integrais (OLIVEIRA et al., 2012).

A importância da equipe de saúde atuando de forma eficiente neste momento é evidenciada pelas percepções de familiares observadas na pesquisa de Walker et al. (2019), onde os mesmos relataram se sentirem mais seguros quando podiam conversar com os profissionais de saúde, ressaltando a necessidade de serem ouvidos e expressarem seus sentimentos.

Considerando o contexto abordado, é essencial que os profissionais de saúde busquem a qualificação através da educação permanente a fim de melhor atender as famílias no processo de doação de órgãos, esclarecendo o funcionamento do percurso da doação, adotando melhores posicionamentos para boa comunicação e entrevista familiar e beneficiando ainda a inteligência emocional pessoal e para apoiar a família enlutada.

Esses aspectos trabalhados por meio de intervenções educativas além de possibilitar um atendimento mais eficaz, também poderiam auxiliar na solução de alguns sentimentos negativos relatados pelos profissionais de saúde, como a insegurança e ansiedade de conversar com os familiares, sensação de despreparo, sobrecarga emocional (DOPSON et al., 2019; MAGALHÃES et al., 2019; PEREIRA et al., 2016), assim como promover uma percepção mais otimista da realidade do processo de doação de órgãos e tecidos para transplantes (SALINAS et al., 2018; VLAISAVLJEVICA et al., 2020).

Algumas dessas medidas educativas poderiam incluir a prática da humanização no atendimento através da escuta ativa e comunicação adequada (OLIVEIRA et al., 2012), acesso ao conhecimento e esclarecimentos, como a compreensão da morte encefálica (AREDES et al., 2018), abertura para conversas e reflexões sobre o processo da doação de órgãos e também sobre a morte e o luto (FARIA eO, 2017), adquirir conhecimentos de técnicas para melhorar a inteligência emocional e como transmitir os conhecimentos de forma eficaz para os familiares atendidos.

A ampliação da percepção e dos conhecimentos dos profissionais poderia auxiliar ainda na motivação dos mesmos para realização dos cuidados desses familiares e especialmente de potenciais doadores em morte encefálica ou circulatória, considerando que os cuidados são motivados pela possibilidade da vida (MAGALHÃES et al., 2019), é essencial conscientizá-los a perceberem o doador como um promotor da vida através da doação. 
Assim, a percepção abrangente, humanizada e qualificada do processo de doação de órgãos beneficiaria tanto o desempenho de trabalho dos profissionais como o apoio e assistência para os familiares que precisam enfrentar essa situação.

\section{CONCLUSÕES}

A análise das percepções subjetivas dos participantes que estiveram envolvidos no processo de doação de órgãos e tecidos para transplantes, tanto de familiares como profissionais, mostrou que existem ainda muitas dúvidas e lacunas no conhecimento de ambos.

Somado a isso, foi fortemente evidenciado a complexidade desse processo e a diversidade de sentimentos que o envolvem, levando a considerar que é preciso abrir mais espaços para reflexões sobre esse delicado tema a fim de melhorar a inteligência emocional.

Estes aspectos de sensibilização e fragilidade que se relacionam com a morte, o luto e o processo de doação de órgãos, remetem a necessidade de humanizar a assistência e realizar o acompanhamento da família de forma integral.

Por fim, a partir das diversas percepções observadas, a maioria dos estudos sugere que intervenções educativas podem auxiliar na melhora da vivência na doação, tanto para profissionais como para os familiares, assim, ressalta-se a importância de facilitar o acesso à informação, da conscientização sobre a realidade da doação de órgãos e esclarecimentos de conceitos associados e da promoção da educação permanente para qualificação dos profissionais de saúde.

\section{REFERÊNCIAS}

AGERSKOV, H.; THIESSON, H.; SPECHT, K.; D PEDERSEN, B.. Parents' experiences of donation to their child before kidney transplantation: a qualitative study. J. Clin. Nurs., v.28, n.910, p.1482-1490, 2019. DOI:

https://doi.org/10.1111/iocn.14734

AHMADIAN, S.; RAHIMI, A.; KHALEGHI, E.. Outcomes of organ donation in brain-dead patient's families: ehical perspective. Nurs Ethics, v.26, n.1, p.256-269, 2019. DOI: https://doi.org/10.1177/0969733017703696

ARANDA, R. S.; ZILLMER, J. G. V.; GONÇALVES, K. D.. Perfil e motivos de negativas de familiares para doação de órgãos e tecidos para transplante. Rev. Baiana Enferm., 2018. DOI: http://doi.org/10.18471/rbe.v32.27560

ARAUJO, C.; SIQUEIRA, M.. Brazilian healthcare professionals: a study of attitudes toward organ donation. Transplant Proc., v.48, n.10, p. 3241-3244, 2016. DOI: http://doi.org/10.1016/j.transproceed.2016.09.044

AREDES, J. S.; FIRMO, J. O. A.; GIACOMIN, K. C.. A morte que salva vidas: complexidades do cuidado médico ao paciente com suspeita de morte encefálica. Cad. Saúde Pública, v.34, n.11, 2018.

ASSOCIAÇÃO BRASILEIRA DE TRANSPLANTES DE ÓRGÃOS. Manual de transplante renal. São Paulo: ABTO, 2010.

BOOKHOLANE, H.; MICHAELIDES, A.; PRINS, L.; STEENKAMP,
L.. Factors influencing consent rates of deceased organ donation in western cape province, South Africa. S. Afr. Med. J., v.110, n.3, p. 204-209, 2020. DOI: http://doi.org/10.7196/SAMJ.2020.v110i3.14227

CAPPELLARO, J.; SILVEIRA, R. S.; LUNARDI, V. L.. Comissão intra-hospitalar de doação de órgãos e tecidos para transplante: questões éticas. Revista da Rede de Enfermagem do Nordeste, v.15, n.6, p.949-956, 2014. DOI: http://doi.org/10.15253/2175-6783.2014000600007

DOPSON, S.; LONG-SUTEHALL, T.. Exploring nurses' knowledge, attitudes and feelings towards organ and tissue donation after circulatory death within the paediatric intensive care setting in the United Kingdom: a qualitative content analysis study. Intensive Crit. Care Nurs, v.54, p.7178, 2019. DOI: http://doi.org/10.1016/i.iccn.2019.07.004

FARIA, S. S.; FIGUEIREDO, J. S.. Aspectos emocionais do luto e da morte em profissionais da equipe de saúde no contexto hospitalar. Psicol. Hosp., v.15, n.1, 2017

FERRAZZO, S.; VARGAS, M. A. O.; MANCIA, J. R.. Crença religiosa e doação de órgãos e tecidos: revisão integrativa da literatura. R. Enferm. UFSM, v.1, n.3, p.449-460, 2011.

FONSECA, P. I. M. N.; TAVARES, C. M. M.; SILVA, T. M. Entrevista familiar para doação de órgãos: conhecimentos necessários segundo coordenadores em transplantes. Res.: Fundam. Care Online, p.3979-3990, 2016. DOI: 


\section{http://doi.org/10.1590/S0103-21002012000500022}

MAGALHÃES, A. L. P.; ERDMANN, A. L.; SOUSA, F. G. M.; LANZONI, G. M. M.. Meaning of nursing care to brain dead potential organ donors. Rev. Gaúcha Enferm., 2018. DOI: http://doi.org/10.1590/1983-1447.2018.2017-0274

MARCONDES, C.; COSTA, A. M. D.; PESSOA, J.. Abordagem familiar para a doação de órgãos: percepção dos enfermeiros. Rev. Enferm UFPE, p.1253-1263, 2019.

MARTINS, E. O.; VALENTE, H. S.; CALAIS, L. B.. As possibilidades de intervenção do psicólogo em favor dos procedimentos de doação de órgãos e transplantes: um relato de experiência. Pesquisas e Práticas Psicossociais, v.11, n.2, p.464-472, 2016.

SALINAS, A. M.; MARTÍNEZ-ISASI, S.; COSTA, E. F.; GARCÍA, A F.. Knowledge and attitudes toward organ donation among health professionals in a third level hospital. Rev. Esp. Salud Publica, v.92, 2018.

MORAN, C. C. M.; RAMOS, E. F.; GÓMEZ-LUJÁN, M. P.. EI amor, resonancia esencial del cuidado para la vida, desde la experiencia del familiar donante renal vivo. Lima (Perú). Salud Uninorte, v.34, n.3, p.687-695, 2018.

OLIVEIRA, I. C.; CUTOLO, L. R. A.. Humanização como expressão de Integralidade. O Mundo da Saúde, v.36, n.3, p.502-506, 2012.

PEREIRA, M. R.; VÁSQUEZ, C. R.; MARTIZ, C. B. Representaciones sociales acerca de la donacón de órganos en enfermeros de una unidad de paciente crítico.

Enfermería: Cuidados Humanizados, v.5, n.2, p.34-40, 2016.
ROSSATO, G. C.; PERLINI, N. M. O. G.; BEGNINI, D.. Doar ou não doar: a visão de familiares frente à doação de órgãos. Rev. Min. Enferm., 2017. DOI: http://doi.org/10.5935/1415$\underline{2762.20170066}$

RUDGE, C.; MATESANZ, R.; DELMONICO, F. L.; CHAPMAN, J. International practices of organ donation. British Journal of Anaesthesia, 2012. DOI: http://doi.org/10.1093/bja/aer399

VICTORINO, J. P.; VENTURA, C. A. A.. Doação de órgãos: tema bioético à luz da legislação. Rev. Bioét., v.25, n.1, p.138-14, 2017

VLAISAVLJEVIC, Z.; JANKOVIC, S.; MAKSIMOVIC, N.; CULAFIC, M.. Attitudes of nurses toward organ donation in Serbia. Transplant Proc., v.52, n.3, p.673-679, 2020. DOI: http://doi.org/10.1016/j.transproceed.2020.01.031

WALKER, R. C.; NAICKER, D.; KARA, T.; PALMER, S. C. Parents' perspectives and experiences of kidney transplantation in children: a qualitative interview study. J. Ren. Care, v.45, n.3, p.193-200, 2019. DOI: http://doi.org/10.1111/jorc.12292

WALKER, W.; SQUE, M.. Family bereavement: a case study of controlled organ donation after circulatory death. Nurs Crit. Care, v.24, n. 4, p.229-234, 2019. DOI: http://doi.org/10.1111/nicc.12436

WESTPHAL, G. A.; GARCIA, V. D.; SOUZA, R. L.. Diretrizes para avaliação e validação do potencial doador de órgãos em morte encefálica. Rev. Bras. Ter. Intensiva, v.28, n.3, p.22055, 2016. DOI: http://doi.org/10.5935/0103-507X.20160049

A CBPC - Companhia Brasileira de Produção Científica (CNPJ: 11.221.422/0001-03) detém os direitos materiais desta publicação. Os direitos referem-se à publicação do trabalho em qualquer parte do mundo, incluindo os direitos às renovações, expansões e disseminações da contribuição, bem como outros direitos subsidiários. Todos os trabalhos publicados eletronicamente poderão posteriormente ser publicados em coletâneas impressas sob coordenação da Sustenere Publishing, da Companhia Brasileira de Produção Científica e seus parceiros autorizados. Os (as) autores (as) preservam os direitos autorais, mas não têm permissão para a publicação da contribuição em outro meio, impresso ou digital, em português ou em tradução. 